\title{
Lycopene Supplementation Attenuates Oxidative Stress Parameters in the Plasma of Humans with Cad after Intense Exercise
}

\author{
-DAC, Lycopene and Exercise
}

\author{
Marília C. Araujo ${ }^{1}$, Fernanda S. Soares ${ }^{1}$, Merieli M. Ronsani ${ }^{1}$, Luiz G. C. Rocha ${ }^{1}$, Lilian C. Vieira ${ }^{2}$, \\ Luciano A. Silva', Tales de Carvalho ${ }^{2}$, Magnus Benetti ${ }^{2}$, Ricardo A. Pinho ${ }^{1}$
}

\footnotetext{
${ }^{1}$ Exercise Biochemistry and Physiology Laboratory, Health Sciences Unit, Universidade do Extremo Sul Catarinense, Criciúma, Brazil; ${ }^{2}$ Cardiology and Medicine Exercise Center, Universidade do Estado de Santa Catarina, Florianópolis, Brazil.

Email: pinho@unesc.net
}

Received February $23^{\text {rd }}, 2011$; revised April 11 ${ }^{\text {th }}, 2011$; accepted April 17 $7^{\text {th }}, 2011$.

\begin{abstract}
To investigate the effects of moderate and intense exercise (ME,IE) and lycopene (L) supplementation on oxidative stress biomarkers in patients with CAD. Rehabilitation clinic.Thirty-two male volunteers with CAD $(55.65 \pm 2.27$ years, $77.27 \pm 3.95 \mathrm{~kg}, 171.9 \pm 2.80 \mathrm{~cm})$ were divided into four groups; ME-Placebo $(n=7), M E+L(n=8)$, IE-Placebo $(n$ $=8)$ and IE-L $(n=9)$. Blood samples $(12 \mathrm{~mL})$ were collected before supplementation (one cereal bars $-15 \mathrm{mg}$ of synthetic lycopene) and exercise (45 min plus $15 \mathrm{~min}$ of stretching, 3/wk) and after five weeks of supplementation and $72 \mathrm{~h}$ after exercise. Nitrite/nitrate concentrations (NOx), lipoperoxidation (TBARS levels), protein carbonylation (PC) and superoxide dismutase (SOD) and catalase (CAT) activity were assessed in plasma. NOx decreased significantly in the $M E-P, I E-P$ and ME-L groups at $72 \mathrm{~h}$ after exercise and increased in the IE-L $72 \mathrm{~h}$ after the last exercise session. The IE-L group demonstrated decreased TBARS at $72 \mathrm{~h}$ after the last exercise session. The level of PC increased only in EI-P at $72 \mathrm{~h}$ after the last exercise session, while only the EI-L group presented a reduction. SOD increased significantly in both placebo groups $72 \mathrm{~h}$ after the last exercise session and decreased in the ME-L group $72 \mathrm{~h}$ after in relation to placebo groups. CAT increased in ME-P, IE-P and IE-L groups only at $72 \mathrm{~h}$ after the last exercise session. The lycopene supplementation attenuates some markers of oxidative stress associated with IE Lycopene also had dissimilar effects on some markers of oxidative stress in subjects undertaking ME versus IE.
\end{abstract}

Keywords: Lycopene, Coronary Artery Disease, Oxidative Stress, Nitric Oxide, Intense Exercise

\section{Introduction}

Coronary artery disease $(\mathrm{CAD})$ is, together with other cardiovascular diseases, one of the main causes of morbidity and mortality in the world and its incidence has been increasing lately in developing countries. According to the World Health Organization (WHO), 3.8 million men and 3.4 million women worldwide die each year from CAD.

Recently, oxidative stress, induced by reactive oxygen species (ROS), has come to be considered to play an important part in the pathophysiology of this disease. Oxidation of the circulating low-density lipoprotein (LDL-ox) is thought to play a key role in the pathogenesis of athe- rosclerosis and CAD. Macrophages inside the arterial wall take up the LDL (ox) and initiate the process of plaque formation [1-3]. Increased ROS inactivates the production of nitric oxide (NO), which accelerates the pathological phenomenon named endothelial dysfunction. Alteration in endothelial function is an initial step in the pathogenesis of atherosclerosis [4].

Moderate aerobic exercise has been used in cardiac rehabilitation programs to improve the symptoms in patients with CAD [5] and to promote the development of antioxidant systems [6-8]. However, some studies have demonstrated that although intense exercise improves the peripheral endothelial function [9-11] it also increases the production of ROS [12]. This contrary effect can be mi- 
nimized by supplementation with antioxidants.

Nutrition also plays an important role in the development of coronary artery disease. Diets rich in fruit and vegetables containing carotenoids have been of interest because of their potential health benefits against chronic diseases such as cardiovascular diseases (CVD) and cancer [13]. Lycopene is a bright red carotenoid pigment, a phytochemical found in tomatoes and other red fruit. Lycopene is the most common carotenoid in the human body as well as being one of the most potent carotenoid antioxidants [14], and has attracted substantial interest for reducing oxidative stress in CVD and other chronic diseases $[15,16]$. The protective effect of tomato or lycopene against oxidation has been shown both in human and animal studies [15,17-19]. A decreased oxidative modification of LDL may be one of the mechanisms by which lycopene may reduce the risk of CVD and atherosclerotic progression $[13,20]$.

Although several authors have suggested that antioxidant supplementation prevents oxidative stress induced by strenuous exercise, only a few studies have used lycopene supplementation to reduce oxidative effects generated by intense exercise and against CAD [21]. Thus, the aim of the present study was to investigate the effects of different intensities of exercise and lycopene supplementation on oxidative stress biomarkers in patients with CAD.

\section{Methods}

\subsection{Subjects}

Thirty-two male volunteers with CAD, documented by angiography, and with an average age of $55.65 \pm 2.27$ years, weight of $77.27 \pm 3.95 \mathrm{~kg}$ and height of $171.9 \pm$ $2.80 \mathrm{~cm}$ were recruited from Cardiosport, a cardiac rehabilitation clinic in Florianopolis, Santa Catarina, Brazil. The criteria for inclusion in the study were: angiographic evidence of $\geq 50 \%$ occlusion of $\geq 1$ major coronary artery, nonsmokers for at least six months, not being on antioxidant supplementation, having participated in physical training (cardiac rehabilitation) for at least six months, not having participated in any other form of structured exercise program for at least six months, absence of recent myocardial infarction and/or revascularization $(<6$ months prior to inclusion in the study), no episodes of unstable angina, decompensated heart failure, life-threatening arrhythmias, known symptomatic aortic outflow obstruction, or severe hypertension $(>180 / 100$ $\mathrm{mm} \cdot \mathrm{Hg}$ ), not undergoing treatment with immunosuppressant/anti-inflammatory agents, and the absence of any severe disease that might compromise the results or be aggravated by physical exercise. All subjects were informed about the purpose of the study and the asso- ciated risks, and all of them gave written informed consent. Approval for this study was obtained from the Ethics Committee of the Universidade do Extremo Sul Catarinense, Criciúma, Santa Catarina, Brazil.

\subsection{Study Design}

This was a single-blind study. Patients were randomly divided into four groups: Moderate Exercise plus Placebo $(\mathrm{ME}-\mathrm{P})(\mathrm{n}=7)$, Moderate Exercise plus Lycopene (MEL) $(\mathrm{n}=8)$, Intense Exercise plus placebo (IE-P) $(\mathrm{n}=8)$ and Intense Exercise plus Lycopene (IE-L) $(\mathrm{n}=9)$. Before beginning the training program, patients performed a cardiopulmonary exercise test on a treadmill (model Super ATL, Imbramed, Brazil), with a ramp protocol. Maximum oxygen uptake $\left(\mathrm{VO}_{2} \max \right)$ was determined by the average respiratory gas exchange ratio using a computerized system (Cortex Metalyzer II, Biophysik, Leipzig, Germany) (data not shown). The $\mathrm{VO}_{2}$ max was defined at the end of treadmill exercise until voluntary cessation or until the patient was unable to maintain the walk/run frequency established by the treadmill, or to any point at which they presented any clinical symptom. Heart rate was monitored throughout the test using a 12lead electrocardiogram (Marquette Medical Systems, Inc. CardioSoft, Wisconsin, USA). Blood pressure was measured using a mercury-column sphygmomanometer before the beginning of the test and during the exercise bout. Food intake of the subjects was determined by a Reminding Questionnaire(RQ) [22]. Subjects were instructed to maintain their usual diet throughout the duration of the study, although with the daily consumption of an average of $10 \mathrm{mg}$ lycopene from several sources (tomato sauce, guava, Surinam cherry, watermelon, papaya), monitored by weekly interviews. In particular, the frequency of consumption of fruit and vegetables was checked to verify compliance with what was agreed.

\subsection{Supplementation}

Cereal bars were produced by Nutrimental S.A. Indústria e Comércio de Alimentos, Curitiba, Brazil, and enriched with $15 \mathrm{mg}$ of synthetic lycopene obtained from Galena Química e Farmacêutica Ltda, Sao Paulo, Brazil.

The placebo bars contained the same ingredients as enriched bars (corn oil, oats, rice crisps, sugar, glucose, maltodextrin), but were devoid of lycopene. Patients were instructed to consume one bar per day for five weeks, i.e. throughout the duration of the study. This supplementation in addition to $10 \mathrm{mg}$ of lycopene from the diet gave a total daily consumption of $25 \mathrm{mg}$, which is recommended by the studies of Rao and Shen [23].

\subsection{Exercise Protocol}

The patients were submitted to a program of cardiac re- 
habilitation at the Cardiosport clinic lasting five weeks, a period considered sufficient to obtain changes in endothelial function [24,25]. Before commencing the training protocol for the study, the subjects had already undergone moderate training for an average period of 4.7 months. The subjects exercised by running on a treadmill at moderate intensity $\left(65 \%-70 \% \mathrm{VO}_{2}\right.$ max, groups ME-P and ME-L) and high intensity $\left(80 \%-85 \% \mathrm{VO}_{2}\right.$ max, groups IE-P and IE-L) for 45 min per session, followed by $15 \mathrm{~min}$ of stretching, three times a week. These aerobic exercise sessions were intercalated by endurance exercise sessions, twice a week. Qualified professionals supervised all exercise sessions and were responsible for monitoring and assessing heart rate.

\subsection{Dietary Assessment}

Dietary nutrient intakes were measured from 3-day food records taken during the supplementation weeks. The patients reviewed the food records, and the nutrient content was determined with the use of specific software (Diet Analysis Plus, ESHA Research, Salem, Oregon, USA) [26].

\subsection{Blood Collection}

Blood samples $(12 \mathrm{~mL})$ were collected from each patient on two occasions: collection 1 (baseline): before supplementation and before commencing the exercise program; collection 2: after five weeks of supplementation and $72 \mathrm{~h}$ after the last exercise session. Blood was obtained in heparinized tubes by venous puncture of the antecubital vein. Plasma was obtained by centrifuging blood samples for $10 \mathrm{~min}$ at $5000 \mathrm{rpm}$. The samples were stored at $-70^{\circ} \mathrm{C}$.

\section{Biochemical Analysis}

\subsection{Plasma Parameters}

Plasma glucose, total cholesterol, LDL-cholesterol, HDL-cholesterol, VLDL-cholesterol and triglyceride levels were determined by standard laboratory methods using certified assays in a local clinical laboratory.

\subsection{Nitrite/Nitrate}

This was determined as previously described [27]. The reaction was based on the enzymatic reduction of nitrate and nitrite in the presence of vanadium (III) combined with detection by the acidic Griess reaction using a colorimetric assay $(540 \mathrm{~nm})$.

\subsection{Oxidative Damage}

The oxidative damage to lipids and proteins was determined in plasma. As an indicator of lipid peroxidation, the formation of substances that react to the heating of thiobarbituric acid (TBARS) was measured spectrophotometrically $(532 \mathrm{~nm})$ and expressed as malondialdehyde equivalents [28]. Oxidative damage in proteins was measured by determining the carbonyl grouping based on the reaction with dinitrophenylhydrazine. Carbonyl content was determined spectrophotometrically $(370 \mathrm{~nm})$ using a coefficient of 22,000 M [29].

\subsection{Antioxidant Enzymes}

Superoxide dismutase (SOD) activity was determined in plasma and assayed by measuring the inhibition of adrenaline autoxidation, as previously described [30]. The CAT activity was determined in erythrocytes and measured by the rate of decrease in hydrogen peroxide absorbance at $240 \mathrm{~nm}$ [31].

\subsection{Protein Determination}

The quantity of proteins in SOD, CAT, TBARS and carbonyl assays was measured using the technique of Lowry [32].

\subsection{Statistical Analysis}

Data were expressed as mean \pm SEM. Statistical analysis was carried out by analysis of variance (ANOVA) followed by appropriate post hoc tests including Tukey's. All analyses were performed using the Statistical Package for the Social Sciences (SPSS) version 15.0 for Windows and a probability value of less than 0.05 was considered as statistically significant.

\section{Results}

\subsection{Plasma Parameters}

The clinical characteristics of the 32 patients are summarized in Table 1. There were no significant differences among the groups in age, height, body mass index, and plasma concentrations of total cholesterol, HDL-cholesterol, LDL-cholesterol, triglycerides, and glucose.

\subsection{Dietary Assessment}

Dietary intake assessed over a 3-day period showed that the supplemented groups had a higher lycopene intake in relation to the placebo groups (Table 2). These data were collected by RQ and the amount of lycopene included the $15 \mathrm{mg}$ from the supplemental energy bars.

\subsection{Nitrate/Nitrite}

According Figure 1, the plasma concentration of NOx decreased significantly in the ME-P, IE-P and ME-L groups $72 \mathrm{~h}$ after the last exercise session when compared with baseline. In addition, an increase was observed in the IE-L group $72 \mathrm{~h}$ after the last exercise session in relation to placebo group. 
Table 1. Anthropometrics characteristics and lipid profile.

\begin{tabular}{|c|c|c|c|c|c|c|c|c|c|c|c|c|c|c|}
\hline \multirow{2}{*}{ Groups } & \multirow{2}{*}{$\begin{array}{c}\text { Age } \\
\text { (Years) }\end{array}$} & \multirow{2}{*}{$\begin{array}{l}\mathrm{BM} \\
(\mathrm{kg})\end{array}$} & \multirow{2}{*}{$\begin{array}{l}\text { Height } \\
(\mathrm{cm})\end{array}$} & \multirow{2}{*}{$\begin{array}{c}\mathrm{BMI} \\
\left(\mathrm{Kg} / \mathrm{m}^{2}\right)\end{array}$} & \multicolumn{2}{|c|}{$\mathrm{TC}(\mathrm{mg} / \mathrm{dL})$} & \multicolumn{2}{|c|}{ HDL (mg/dL) } & \multicolumn{2}{|c|}{ LDL (mg/dL) } & \multicolumn{2}{|c|}{ VLDL (mgdL) } & \multicolumn{2}{|c|}{$\mathrm{TG}(\mathrm{mg} / \mathrm{dL})$} \\
\hline & & & & & Before & After & Before & After & Before & After & Before & After & Before & After \\
\hline $\begin{array}{l}\text { EM- } \\
\text { Placebo }\end{array}$ & $\begin{array}{c}55.5 \\
(4.13)\end{array}$ & $\begin{array}{c}85 \\
(5.44)\end{array}$ & $\begin{array}{l}173.7 \\
(2.83)\end{array}$ & $\begin{array}{l}28.29 \\
(2.35)\end{array}$ & $\begin{array}{l}183.33 \\
(22.26)\end{array}$ & $\begin{array}{l}168.67 \\
(24.86)\end{array}$ & $\begin{array}{l}58.33 \\
(6.74)\end{array}$ & $\begin{array}{l}53.00 \\
(4.04)\end{array}$ & $\begin{array}{l}126.00 \\
(4.90)\end{array}$ & $\begin{array}{l}110.00 \\
(16.33)\end{array}$ & $\begin{array}{l}35.00 \\
(6,50)\end{array}$ & $\begin{array}{c}22.67 \\
(11.46)\end{array}$ & $\begin{array}{l}178.33 \\
(12.85)\end{array}$ & $\begin{array}{l}136.67 \\
(16.68)\end{array}$ \\
\hline $\begin{array}{l}\text { EM- } \\
\text { Lycopene }\end{array}$ & $\begin{array}{l}55.17 \\
(1.60)\end{array}$ & $\begin{array}{l}72.71 \\
(2.66)\end{array}$ & $\begin{array}{l}172.0 \\
(2.02)\end{array}$ & $\begin{array}{l}24.53 \\
(0.55)\end{array}$ & $\begin{array}{l}140.33 \\
(6.05)\end{array}$ & $\begin{array}{l}165.67 \\
(11.15)\end{array}$ & $\begin{array}{l}55.67 \\
(1.75)\end{array}$ & $\begin{array}{l}59.00 \\
(2.93)\end{array}$ & $\begin{array}{l}78.67 \\
(5.62)\end{array}$ & $\begin{array}{l}91.33 \\
(9.29)\end{array}$ & $\begin{array}{l}16.67 \\
(1,31)\end{array}$ & $\begin{array}{l}16.67 \\
(2.80)\end{array}$ & $\begin{array}{l}83.67 \\
(6.67)\end{array}$ & $\begin{array}{c}85.67 \\
(14.22)\end{array}$ \\
\hline $\begin{array}{l}\text { EI- } \\
\text { Placebo }\end{array}$ & $\begin{array}{c}56.60 \\
(1.9)\end{array}$ & $\begin{array}{l}73.87 \\
(4.3)\end{array}$ & $\begin{array}{c}170 \\
(3.7)\end{array}$ & $\begin{array}{l}25.22 \\
(1.06)\end{array}$ & $\begin{array}{l}155.32 \\
(5.98)\end{array}$ & $\begin{array}{l}161.88 \\
(4.21)\end{array}$ & $\begin{array}{l}49.99 \\
(3.78)\end{array}$ & $\begin{array}{l}51.39 \\
(2.88)\end{array}$ & $\begin{array}{l}101.87 \\
(4.71)\end{array}$ & $\begin{array}{l}97.39 \\
(7.44)\end{array}$ & $\begin{array}{l}28.23 \\
(4,99)\end{array}$ & $\begin{array}{l}24.24 \\
(3.93)\end{array}$ & $\begin{array}{l}159.26 \\
(8.07)\end{array}$ & $\begin{array}{l}145.09 \\
(18.67)\end{array}$ \\
\hline $\begin{array}{l}\text { EI- } \\
\text { Lycopene }\end{array}$ & $\begin{array}{l}55.33 \\
(1.44)\end{array}$ & $\begin{array}{l}77.51 \\
(3.38)\end{array}$ & $\begin{array}{l}171.9 \\
(2.62)\end{array}$ & $\begin{array}{l}26.20 \\
(0.95)\end{array}$ & $\begin{array}{l}149.67 \\
(1,37)\end{array}$ & $\begin{array}{l}155.50 \\
(8.40)\end{array}$ & $\begin{array}{l}42.67 \\
(3.14)\end{array}$ & $\begin{array}{l}38.00 \\
(4.55)\end{array}$ & $\begin{array}{l}89.67 \\
(1.03)\end{array}$ & $\begin{array}{l}92.00 \\
(6.66)\end{array}$ & $\begin{array}{l}34.33 \\
(6.10)\end{array}$ & $\begin{array}{l}30.00 \\
(6.51)\end{array}$ & $\begin{array}{l}173,00 \\
(31.55)\end{array}$ & $\begin{array}{l}152.50 \\
(32.99)\end{array}$ \\
\hline
\end{tabular}

Note: Values are expressed as mean \pm SEM. BM: body mass; BMI: body mass index; TC: total cholesterol; HDL: high density lipoprotein; LDL: low density lipoprotein; VLDL: very low density lipoprotein; TG: triglycerides.

Table 2. Mean dietary intake assessed over 3 days for patients with CAD provided lycopene supplement.

\begin{tabular}{ccccccc}
\hline Group & Kcal & Protein (\%) & Carbohydrate (\%) & Fat (\%) & Vitamin C (mg) & Lycopene (mg) \\
\hline $\begin{array}{c}\text { Supplemented } \\
\text { groups }\end{array}$ & $2311.56 \pm 101.71$ & $18.03 \pm 0.61$ & $53.95 \pm 1.39$ & $28.00 \pm 1.59$ & $225.23 \pm 40.90$ & $27.58^{*} \pm 1.86$ \\
Placebo groups & $2027.39 \pm 245.10$ & $15.05 \pm 0.87$ & $59.21 \pm 2.14$ & $25.75 \pm 1.90$ & $292.76 \pm 58.51$ & $8.32 \pm 1.27$ \\
\hline
\end{tabular}

Note: Values are expressed as mean \pm SEM and the significant difference $(*)$ used was from $\mathrm{p}<0.05$.

\subsection{Oxidative Damage}

The IE-L group showed significantly decreased TBARS levels $72 \mathrm{~h}$ after the last exercise session when compared with baseline and the corresponding control (Figure 2). In contrast to lipoperoxidation, the level of protein carbonylation increased only in the IE-P group $72 \mathrm{~h}$ after the last exercise session, while only the IE-L group presented a significant reduction in relation to the basal and placebo groups during the same period (Figure 3).

\subsection{Antioxidant Enzymes}

In relation to SOD activity, the Figure 4 show a significant increase in the ME-P and IE-P groups at $72 \mathrm{~h}$ after the last exercise session, while the values for the ME-L and IE-L groups were unaffected. Meanwhile, there was a decrease in the ME-L and IE-L groups $72 \mathrm{~h}$ after exercise, both when compared to the placebo groups. CAT activity increased in the ME-P, IE-P and IE-L groups only $72 \mathrm{~h}$ after the last exercise session (Figure 5).

\section{Discussion}

Oxidative stress appears to play an important role in the etiology of coronary heart disease $[1,33]$ and some studies have demonstrated the benefits of the physical exercise on cardiovascular diseases [5-7,11]. However, the effects of physical training are associated with the intensity of the exercise, among other factors. The although intense exercise improves the peripheral endothelial function [9-11] it also increases the production of ROS [12]. This contrary effect can be minimized by supplementation with antioxidants. Thus, this study hypothesized that regular exercise and lycopene supplementation could ameliorate oxidative stress biomarkers present in CAD.

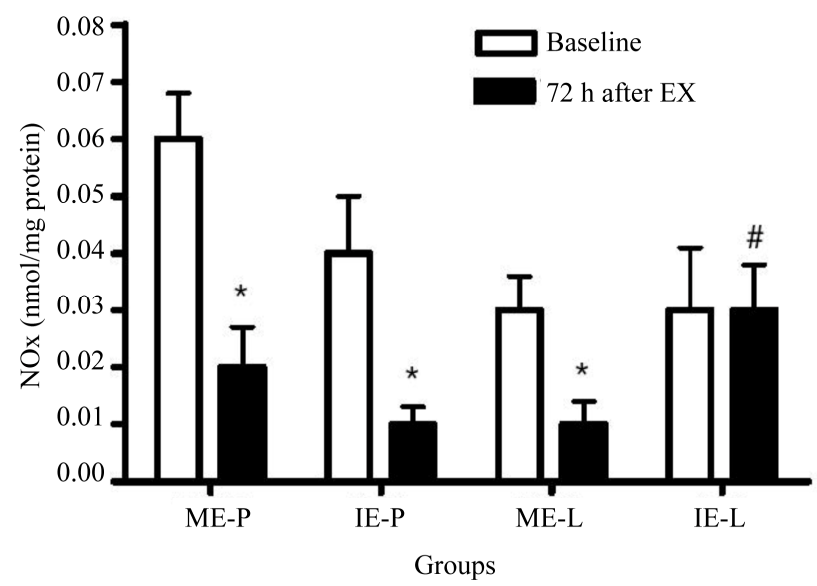

Figure 1. Effects of lycopene supplementation and different intensities of exercise training on plasma nitrite/nitrate concentration of patients with CAD. Values are expressed as mean \pm SEM and the results expressed in nmol of $\mathrm{NOx} / \mathrm{mg}$ of proteins. Significant difference in relation to the respective control group $\left(^{\#}\right)$ and in relation to baseline $(*) ; p<0.05$. 


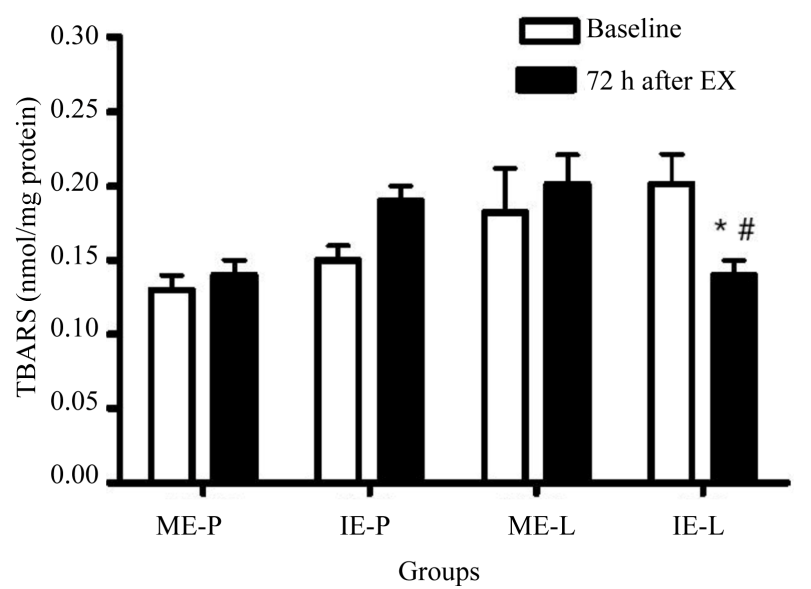

Figure 2. Effects of lycopene supplementation and different intensities of exercise training on lipoperoxidation levels of patients with CAD. Values are expressed as mean \pm SEM and the results expressed in nmol of TBARS level/mg of protein. Significant difference in relation to the respective control group (*) and in relation to baseline (*); $\mathbf{p}<0.05$.

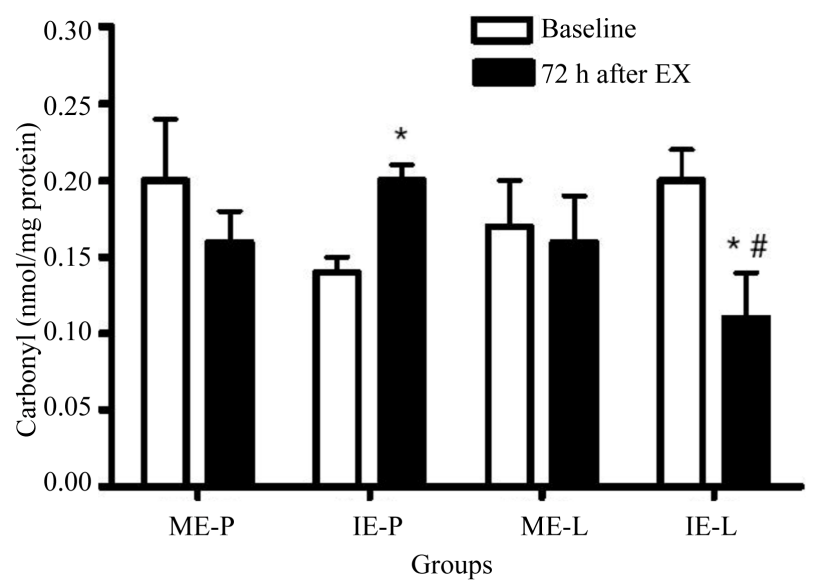

Figure 3. Effects of lycopene supplementation and different intensities of exercise training on carbonylation levels of patients with CAD. Values are expressed as mean \pm SEM and the results expressed in $\mathbf{n m o l} / \mathbf{m g}$ of protein. Significant difference in relation to the respective control group $\left(^{*}\right)$ and in relation to baseline $\left(^{*}\right) ; p<0.05$.

The present study is one of the few investigations that assess the effects of antioxidant supplement in human with CAD after intense exercise. Lycopene was used as antioxidant agent. However, for technical problems it was not possible to measure the blood level lycopene, only estimation by dietary questionnaire. This is a limitation, but it doesn't commit the results and the conclusions of study.

NO produced in the vascular endothelial cells has a potent vasodilatory effect and has been proposed to have antiatherosclerotic properties. Therefore, altered plasma NO concentrations may have important clinical signifi-

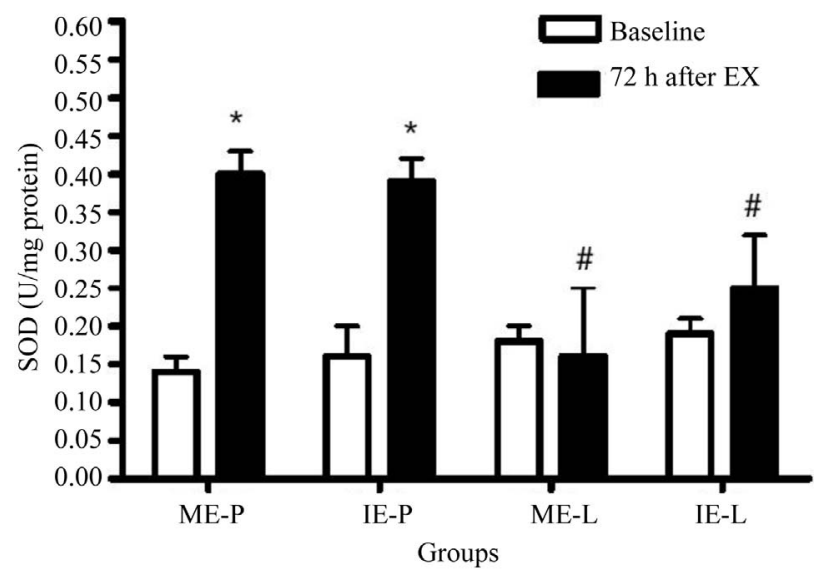

Figure 4. Effects of lycopene supplementation and different intensities of exercise training on SOD activity in patients with CAD. Values are expressed as mean \pm SEM and the results expressed in U SOD/mg protein. Significant difference in relation to the respective control group $(*)$ and in relation to baseline $(*) ; \mathbf{p}<0.05$.

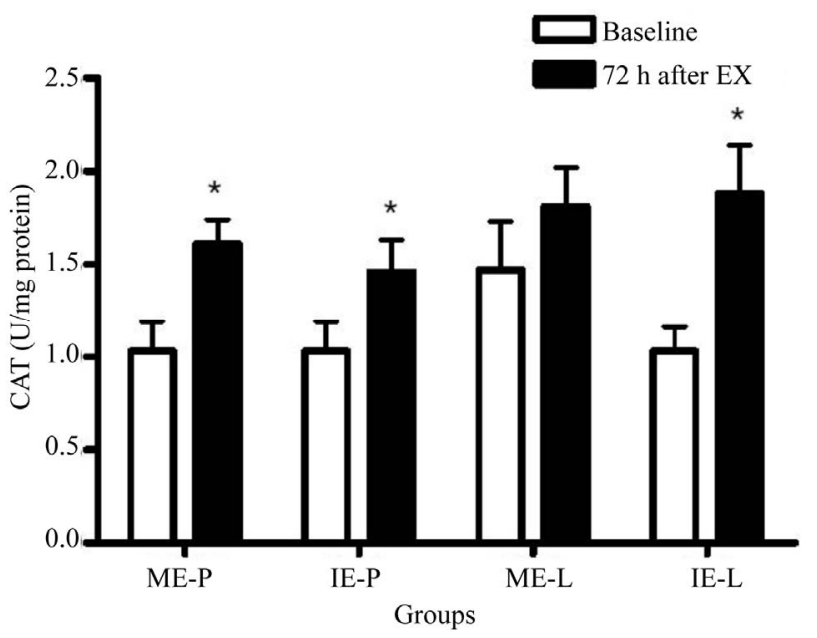

Figure 5. Effects of lycopene supplementation and different intensities of exercise training on CAT activity in patients with CAD. Values are expressed as mean \pm SEM and the results expressed in $U \mathrm{CAT} / \mathrm{mg}$ protein. Significant difference in relation to the respective control group ( $\left.{ }^{\#}\right)$ and in relation to baseline $(*) ; p<0.05$.

cance [34] In the present study, plasma NOx concentration decreased significantly after moderate exercise. This is quite an unexpected finding, since it is well known that exercise training is associated with an increase in vascular shear stress resulting from increased flow, which stimulates the release of NO with consequent vasodilation $[7,9]$.

These findings suggest that oxidative modifications present in CAD may be a major mechanism capable of justifying the vascular impairment. In addition, there is evidence that atherosclerosis represents a state of heigh- 
tened oxidative stress, which alters the bioavailability of NO leading to an endothelial dysfunction $[1,3,35]$, and that in this study could not be reversed by lycopene supplementation and moderate exercise training.

On the other hand, higher NOx concentrations were observed in the IE-L group in relation to the placebo group, a result that is corroborated by the literature [9-11]. Matsumoto and colleagues [36] reported that the production of NO progressively increases as exercise intensity increases, although some studies have suggested that long-term intense (anaerobic) exercise may impair endothelium-dependent vasodilation through decreases in levels of antioxidants and an increase in reactive oxygen species, resulting in a reduction in NO bioavailability $[37,38]$.

It has also been pointed out by several research groups that $\mathrm{CAD}$ and high-intensity exercise are linked to oxidative damage, significantly increasing lipid peroxidation and protein carbonylation in plasma and muscle, and significantly decreasing the antioxidants content $[5,25$, 39,40] Furthermore, it has been demonstrated that the intake of lycopene-rich food or lycopene supplementation is able to decrease oxidative damage [15,25,40-42]. The reduction of TBARS level and carbonyl groups in the IE-L group suggests that lycopene can indeed attenuate the process of oxidative damage. The lycopene intake can modify the cellular levels of antioxidants and prooxidants, making membranes less susceptible to oxidation reactions [43]. Metabolism of lycopene, or a range of metabolites and oxidative products called lycopenoids, has an antioxidant and antiproliferative action that has been identified in vivo and in vitro [44,45]. Metabolites and oxidative products of lycopene could act in synergy with other endogenous antioxidant substances [46], which could provide an explanation as to why lycopene reduced this oxidative damage. In addition, little is known about the role of lycopene in the prevention of oxidative damage to proteins, which are among the major cell constituents, and any damage to which could result in the loss of functionality of enzymes, receptors and membrane transporters [47]. The formation of carbonyl groups on protein side chains is considered to be a marker of severe oxidative stress and the severity of disease.

In relation to the antioxidant defenses, the increase observed in SOD activity only in placebo groups suggests the antioxidant effect of lycopene on the production of oxidants $[40,48]$. It is possible that lycopene undergoes a reversible electron transfer with the superoxide radical, reducing the production of oxidant. However, supplementation did not alter the CAT activity. It is possible that the difference observed among the enzymes is due, primarily, to the difference in the analyzed material, since SOD was determined in plasma while CAT was determined in erythrocytes. Secondly, the catalysis of hydrogen peroxide might also be being conducted by glutathione peroxidase.

In conclusion, the observations of the present study show that intense exercise increases plasma concentrations of NO in patients with CAD supplemented with synthetic lycopene and that this supplementation is also able to reduce oxidative damage. However, lycopene attenuated some, but not all, markers of oxidative stress associated with intense exercise. In additional, lycopene had dissimilar effects on some markers of oxidative stress in subjects undertaking moderate exercise versus intense exercise. These observations support the notion that oxidative modifications play an essential role in CAD.

\section{Author Contributions}

All authors participated of study and made substantial contributions in the conception and design of the study, or acquisition of data, or analysis and interpretation of data, drafting the article or revising it critically for important intellectual content. MCA, TC, MB and RAP wrote and reviewed the manuscript, FSS, MMP, LGCR and LCV conducted the experiments.

\section{Acknowledgements}

The authors thank Nutrimental S.A. Indústria e Comércio de Alimentos and Cardiosport for all their support and collaboration and Unesc, Capes and CNPq for financial support.

\section{REFERENCES}

[1] U. Singh and I. Jialal, "Oxidative Stress and Atherosclerosis," Pathophysiology, Vol. 13, No. 3, 2006, pp. 129-142. doi:10.1016/j.pathophys.2006.05.002

[2] N. R. Madamanchi, A. Vendrov and M. S. Runge, "Oxidative Stress and Vascular Disease," Arteriosclerosis, Thrombosis, and Vascular Biology, Vol. 25, No. 1, 2005, pp. 29-38.

[3] C. Antoniades, D. Tousoulis, C. Tentolouris, P. Toutouzas and C. Stefanadis, "Oxidative Stress, Antioxidant Vitamins, and Atherosclerosis," Herz, Vol. 28, No. 7, 2003, pp. 628-638. doi:10.1007/s00059-003-2417-8

[4] H. Cai and D. G. Harrison, "Endothelial Dysfunction in Cardiovascular Diseases; the Role of Oxidative Stress," Circulation Research, Vol. 87, No. 10, 2000, pp. 840-844.

[5] H. D. Sesso, R. S. Paffenbarger Jr. and I. M. Lee, "Physical Activity and Coronary Heart Disease in Men: The Harvard Alumni Health Study," Circulation, Vol. 102, 2000, pp. 975-980.

[6] S. A. Marsh and J. S. Coombes, "Exercise and the Endothelial Cell," International Journal of Cardiology, Vol. 99, No. 2, 2005, pp. 165-169. doi:10.1016/j.ijcard.2004.02.005 
[7] F. Farsidfar, E. Kasikcioglu, H. Oflaz, D. Kasikcioglu, M. Meric and S. Umman, "Effects of Different Intensities of Acute Exercise on Flow-Mediated Dilatation in Patients with Coronary Heart Disease," International Journal of Cardiology, Vol. 124, No. 3, 2008, pp. 372-374. doi:10.1016/j.ijcard.2006.11.243

[8] M. C. Gomez-Cabrera, E. Domenech, L. L. Ji and J. VIña, "Exercise as an Antioxidant: It Up-Regulates Important Enzymes for Cell Adaptations to Exercise," SCI Sports, Vol. 21, No. 2, 2006, pp. 85-89.

[9] C. Goto, Y. Higashi, M. Kimura, K. Noma, K. Hara, K. Nagawa, M. Kawamura, K. Chayana, M. Yoshizumi and I. I. Nara, "Effect of Different Intensities of Exercise on Endothelium-Dependent Vasodilation in Humans: Role of Endothelium-Dependent Nitric Oxide and Oxidative Stress," Circulation, Vol. 108, No. 5, 2003, pp. 530-535. doi:10.1161/01.CIR.0000080893.55729.28

[10] M. Benetti, H. Cascaes and T. Carvalho, "The Impact of Different Aerobic Exercise Intensity on Endothelial Function in Patients Post Myocardial Infarction," Journal of the American College of Cardiology, Vol. 49, 2007, p. 30.

[11] U. Wisløff, A. Støylen, J. P. Loennechen, M. Bruvold, O. Rognmo, P. M. Haram, A. E. Tjønna, J. Helgerud, S. A. Slørdahl, S. J. Lee, V. Videm, A. Bye, G. L. Smith, S. M. Najjar, O. Ellingsen and T. Skjaerpe, "Superior Cardiovascular Effect of Aerobic Interval Training Versus Moderate Continuous Training in Heart Failure Patients," Circulation, Vol. 115, No. 24, 2007, pp. 3086-3094.

[12] P. M. Clarkson and H. S. Thompson, "Antioxidants: What Role do They Play in Physical Activity and Health?" The American Journal of Clinical Nutrition, Vol. 72, No. 3, 2000, pp. 637-646.

[13] T. Rissanen, S. Voutilainen, K. Nyyssonen and J. T. Salonen, "Lycopene, Atherosclerosis, and Coronary Heart Disease," Experimental Biology and Medicine, Vol. 227, No. 10, 2002, pp. 900-907.

[14] A. Blum, M. Monir, I. Wirsansky and S. Ben-Arzi, "The Beneficial Effects of Tomatoes," European Journal of Internal Medicine, Vol. 16, No. 6, 2005, pp. 402-404. doi:10.1016/j.ejim.2005.02.017

[15] S. Agarwal and A. V. Rao, "Tomato Lycopene and Its Role in Human Health and Chronic Diseases," Canadian Medical Association Journal, Vol. 19, No. 6, 2000, pp. 163-166.

[16] J. Gianetti, R. Pedrinelli, R. Petrucci, G. Lazzerini, M. De Caterina, G. Bellomo and R. De Caterina, "Inverse Association between Carotid Intima-Media Thickness and the Antioxidant Lycopene in Atherosclerosis," American Heart Journal, Vol. 143, No. 3, 2002, pp. 467-474. doi:10.1067/mhj.2002.120776

[17] D. K. Lee, R. N. Grantham, J. D. Mannion and A. L. Trachte, "Carotenoids Enhance Phosphorylation of Akt and Suppress Tissue Factor Activity in Human Endothelial Cells," The Journal of Nutritional Biochemistry, Vol. 17, No. 11, 2006, pp. 780-786. doi:10.1016/i.jnutbio.2006.01.006

[18] K. Sahin, M. Onderci, N. Sahin, M. F. Gursu, F. Khachik and O. Kucuk, "Effects of Lycopene Supplementation on Antioxidant Status, Oxidative Stress, Performance and Carcass Characteristics in Heat-Stressed Japanese Quail," Journal of Thermal Biology, Vol. 31, No. 4, 2006, pp. 307-312. doi:10.1016/j.jtherbio.2005.12.006

[19] K. D. K. Ahuja, J. K. Pittaway and M. J. Ball, "Effects of Olive Oil and Tomato Lycopene Combination on Serum Lycopene, Lipid Profile, and Lipid Oxidation," Nutrition, Vol. 22, No. 3, 2006, pp. 259-265. doi:10.1016/j.nut.2005.07.015

[20] D. Heber and Q. Lu, "Overview of Mechanisms of Action of Lycopene," Experimental Biology and Medicine, Vol. 227, No. 10, 2002, pp. 920-923.

[21] C.-C. Liu, et al., "Lycopene Supplementation Attenuated Xanthine Oxidase and Myeloperoxidase Activities in Skeletal Muscle Tissues of Rats after Exhaustive Exercise," British Journal of Nutrition, Vol. 94, No. 4, 2005, pp. 595-601. doi:10.1079/BJN20051541

[22] H. J. Montoye, H. C. G. Kemper, W. H. M. Saris and R. A. Washburn, "Measuring Physical Activity and Energy Expenditure," Human Kinetics, Champaign, 1996.

[23] A. V. Rao and H. Shen, "Effect of Low Dose Lycopene Intake on Lycopene Bioavailability and Oxidative Stress," Nutrition Research, Vol. 22, No. 7, 2002, pp. 1125-1131. doi:10.1016/S0271-5317(02)00430-X

[24] A. Maiorana, G. O'Driscoll, C. Cheetham, L. Dembo, K. Stanton, C. Goodman, R. Taylor and D. Green, "The Effect of Combined Aerobic and Resistance Training on Vascular Function in Type 2 Diabetes," Journal of the American College of Cardiology, Vol. 38, No. 3, 2001, pp. 860-866. doi:10.1016/S0735-1097(01)01439-5

[25] C. A. Desouza, et al., "Regular Aerobic Exercise Prevents and Restores Age-Related Declines in Endothelium-Dependent Vasodilation in Healthy Men," Circulation, Vol. 102, No. 12, 2000, pp. 1351-1357.

[26] R. J. Bloomer, A. H. Goldfarb, M. J. McKenzie, T. You and L. Nguyen, "Effects of Antioxidant Therapy in Women Exposed to Eccentric Exercise," International Journal of Sport Nutrition and Exercise Metabolism, Vol. 14, No. 4, 2004, pp. 377-388.

[27] K. M. Miranda, M. G. Espey and D. A. Wink, "A Rapid, Simple Spectrophotometric Method for Simultaneous Detection of Nitrate and Nitrite," Nitric Oxide, Vol. 5, No. 1, 2001, pp. 62-71. doi:10.1006/niox.2000.0319

[28] H. H. Drapper and M. Hadley, "Malondialdehyde Determination as Index of Lipid Peroxidation," Meth Enzymol, Vol. 186, No. 9, 1990, pp. 421-431. doi:10.1016/0076-6879(90)86135-I

[29] R. L. Levine, D. Garland, C. N. Oliver, A. Amici, I. Climent, A. G. Lenz, B. W. Ahn, S. Shaltiel and S. E. R. Stadtman, "Determination of Carbonyl Content in Oxidatively Modified Proteins," Meth Enzymol, Vol. 186, 1990, pp. 464-478. doi:10.1016/0076-6879(90)86141-H

[30] J. V. Bannister and L. Calabrese, "Assay for SOD," Methods of Biochemical Analysis, Vol. 32, 1987, pp. 279312. doi:10.1002/9780470110539.ch5

[31] H. Aebi, "Catalase in Vitro," Meth Enzymol, Vol. 105, 
1984, pp. 121-126. doi:10.1016/S0076-6879(84)05016-3

[32] O. H. Lowry, N. G. Rosebough, A. L. Farr and R. J. Randall, "Protein Measurement with the Folin Phenol Reagent," The Journal of Biological Chemistry, Vol. 193, 1951, pp. 265-275.

[33] A. C. Kaliora, G. V. Z. Dedoussis and H. Schmidt, "Dietary Antioxidants in Preventing Atherogenesis," Atherosclerosis, Vol. 187, No. 1, 2006, pp. 1-17. doi:10.1016/j.atherosclerosis.2005.11.001

[34] S. Maeda, T. Otsuki, M. Iemitsu, M. Kamioka, J. Sugawara, S. Kuno, R. Ajisaka and H. Tanaka, "Effects of Leg Resistance Training on Arterial Function in Older Men," British Journal of Sports Medicine, Vol. 40, No. 10, 2006, pp. 867-869. doi:10.1136/bjsm.2006.029538

[35] J. Kals, P. Kampus, M. Kals, K. Zilmer, T. Kullisaar, R. Teesalu, A. Pulges and M. Zilmer, "Impact of Oxidative Stress on Arterial Elasticity in Patients with Atherosclerosis," American Journal of Hypertension, Vol. 19, No. 9, 2006, pp. 902-908.

[36] A. Matsumoto, Y. Hirata, S. Momomura, H. Fujita, A. Yao, M. Sata and T. Serizawa, "Increased Nitric Oxide Production during Exercise," Lancet, Vol. 343, No. 8901, 1994, pp. 849-850. doi:10.1016/S0140-6736(94)92047-8

[37] K. J. Davies, A. T. Quintanilha, G. A. Brooks and L. Packer, "Free Radicals and Tissue Damage Produced by Exercise," Biochemical and Biophysical Research Communications, Vol. 107, No. 4, 1982, pp. 1198-1205. doi:10.1016/S0006-291X(82)80124-1

[38] R. Bergholm, S. Mäkimattila, M. Valkonen, M. L. Liu, S. Lahdenperä, M. R. Taskinen, A. Sovijärvi, P. Malmberg and H. Yki-Järvinen, "Intense Physical Training Decreases Circulating Antioxidants and Endothelium-Dependent Vasodilatation in Vivo," Atherosclerosis, Vol. 145, No. 2, 1999, pp. 341-349. doi:10.1016/S0021-9150(99)00089-1

[39] J. L. S. Quesada, H. Ortega, R. A. Payes, S. J. Serrat, S. F. Gonzalez, M. A. Lasuncion and L. J. Ordonez, "LDL from Aerobically-Trained Subjects Shows Higher Resistance to Oxidative Modification than LDL from Sedentary Subjects," Atherosclerosis, Vol. 132, No. 2, 1997, pp. 207-213. doi:10.1016/S0021-9150(97)00108-1

[40] K. S. C. Bose and B. K. Agrawal, "Effect of Lycopene from Cooked Tomatoes on Serum Antioxidant Enzymes, Lipid Peroxidation Rate and Lipid Profile in Coronary Heart Disease," Singapore Medical Association, Vol. 48, No. 5, 2007, pp. 415-420.

[41] F. Visioli, P. Riso, S. Grande, C. Galli and M. Porrini, "Protective Activity of Tomato Products on in Vivo Markers of Lipid Oxidation," European Journal of Nutrition, Vol. 42, No. 4, 2003, pp. 201-206. doi:10.1007/s00394-003-0415-5

[42] K. Jacob, et al., "Influence of Lycopene and Vitamin C from Tomato Juice on Biomarkers of Oxidative Stress and Inflammation," British Journal of Nutrition, Vol. 99, No. 1, 2008, pp. 137-146. doi:10.1017/S0007114507791894

[43] E. A. Moreira, R. L. Fagundes, D. W. Filho, D. Neves, F. Sell, F. Bellisle and E. Kupek, "Effects of Diet Energy Level and Tomato Powder Consumption on Antioxidant Status in Rats," Clinical Nutrition, Vol. 24, No. 6, 2005, pp. 1038-1046. doi:10.1016/j.clnu.2005.08.005

[44] O. Aust, N. Ale-Agha, L. Zhang, H. Wollersen, H. Sies and W. Stahl, " Lycopene Oxidation Product Enhances Gap Functional Communication," Food and Chemical Toxicology, Vol. 41, No. 10, 2003, pp. 1399-1407. doi:10.1016/S0278-6915(03)00148-0

[45] B. L. Lindshield, K. Canene-Adams and J. W. Erdman Jr., "Lycopenoids: Are Lycopene Metabolites Bioactive?" Archives of Biochemistry and Biophysics, Vol. 458, No. 2, 2006, pp. 136-140. doi:10.1016/j.abb.2006.09.012

[46] D. Gitenay, B. Lyan, M. Rambeau, A. Mazur and E. Rock, "Comparison of Lycopene and Tomato Effects on Biomarkers of Oxidative Stress in Vitamin E Deficient Rats," European Journal of Nutrition, Vol. 46, No. 8, 2007, pp. 468-475. doi:10.1007/s00394-007-0687-2

[47] A. Salvi, P. A. Carrupt, J. P. Tillement and B. Testa, "Structural Damage to Proteins Caused by Free Radicals: Assessment, Protection by Antioxidants, and Influence of Protein Binding," Biochemical Pharmacology, Vol. 61, No. 10, 2001, pp. 1237-1242. doi:10.1016/S0006-2952(01)00607-4

[48] B. Halliwell and J. M. C. Gutteridge, "Free Radicals in Biology and Medicine," University Press, Oxford, 2007. 